\title{
Asthma Mortality in Male Workers of the Dye Industry in Korea
}

\author{
Dong-Hee $\mathrm{KoH}^{1}$, Jonguk Won ${ }^{2}$, Yeon-Soon $\mathrm{AHN}^{3}$, Hyoung-Ryoul $\mathrm{KIm}^{4}$ and \\ Sang-Beak $\mathrm{KoH}^{5}$
}

${ }^{1}$ Occupational Safety and Health Research Institute, Korea Occupational Safety and Health Agency (KOSHA), ${ }^{2}$ Department of Preventive Medicine, Yonsei University College of Medicine, Institute for Occupational Health, ${ }^{3}$ Department of Occupational Medicine, Dongguk University International Hospital, Dongguk University College of Medicine, ${ }^{4}$ Department of Preventive Medicine and Industrial Medical Center, The Catholic University of Korea and ${ }^{5}$ Department of Preventive Medicine and Institute of Occupational Medicine, Yonsei University Wonju College of Medicine, Korea

\begin{abstract}
Asthma Mortality in Male Workers of the Dye Industry in Korea: Dong-Hee $\mathrm{KoH}$, et al. Occupational Safety and Health Research Institute, Korea Occupational Safety and Health Agency, Korea-Workers in the dye industry are exposed to various chemicals, of which reactive dye is a wellknown occupational asthmagen. This study examined the relationship between asthma mortality and occupational exposure in the dye industry. The cohort comprised 66,089 male workers, including 904 workers in the dye industry, who underwent medical examinations from 1995 to 2003 at a medical service institute located in Incheon, Korea. Deaths were also observed during the 1995 to 2003 period. The mortality was analyzed using the standardized mortality ratio (SMR) compared to the Korean general population, and the mortalities from asthma in dye manufacturing workers and other workers were compared using the standardized rate ratio (SRR). The all-cause mortality in dye industry workers was significantly lower than in the general population (SMR $=0.40,95 \% \mathrm{Cl} 0.24-0.63$ ), while the asthma mortality $(\mathrm{SMR}=9.03,95 \% \mathrm{Cl} 1.86$ 26.39) was significantly higher. Deaths from nonmalignant respiratory diseases were higher in dye industry workers, but were not statistically significant (SMR=2.0, 95\% Cl 0.41-5.86). In the internal comparison, the all-cause mortality was the same in both groups, while the mortalities from non-malignant respiratory diseases $(\mathrm{SRR}=6.04,95 \% \mathrm{Cl} 4.00-9.44)$ and asthma (SRR $=23.29,95 \% \mathrm{Cl} 11.05-58.83)$ were higher in dye industry workers than in workers in other industries. Because asthma is a life-threatening disease, special consideration and preventive
\end{abstract}

Received Sep 6, 2007; Accepted Nov 24, 2007

Correspondence to: J. Won, Department of Preventive Medicine, Yonsei University College of Medicine, CPO Box 8044, Seoul 120 752, Korea (e-mail: juwon@yuhs.ac) measures must be taken for workers in the dye industry. (J Occup Health 2008; 50: 130-135)

Key words: Asthma, Occupational, Dye, Reactive dye, Mortality

Workers in the dye industry are exposed to many hazardous chemicals, such as the carcinogens $\beta$ naphthylamine and benzidine. Some dyes are well-known occupational asthmagens, such as reactive dye, and in Korea, dye industry workers have been compensated for occupational asthma since 1988. Moreover, reactive dye was one of the most frequent causes of compensated occupational asthma in Korea until the 1990s.

Reactive dye, a potent asthmagen, has been used worldwide since 1956 for dying cotton and wool ${ }^{1)}$. In Korea, the production of reactive dye began in the 1970s. In European countries, the production of $\beta$-naphthylamine was banned between the 1930s and 1950s, while that of benzidine was banned between the 1950s and 1970s; both are known urological carcinogens. In Japan, the production and use of benzidine, $\beta$-naphthylamine, 4 aminophenyl, and 4-nitrobiphenyl are banned and the Japanese government shut down dye manufacturing in $1972^{2)}$. Since then, the Korean dye manufacturing industry has expanded markedly through the transfer of these technologies from Japan ${ }^{3)}$. Nevertheless, in Korea, benzidine chloride and the manufacture of benzidinebased dyes have been prohibited since 2000 .

Occupational asthma, now mainly due to isocyanates, has become an emerging issue in Korea, and many new industrial materials causing asthma are being reported ${ }^{4}$.

Asthma is a chronic inflammatory disorder of the airways characterized by variable airflow obstruction and airway hyperresponsiveness ${ }^{5)}$. Asthma can be lifethreatening, but few studies have examined the 
occupational mortality of the disease. Some studies, however, have elucidated the relationship by occupation, and others by industry, such as in pulp and paper workers, sulfite mill workers, and ferroalloy plants ${ }^{6-9}$.

We investigated the excess risk of death due to asthma in dye workers. This study examined 66,089 workers, including 904 workers in the dye industry, who underwent medical examinations between 1995 and 2003 in a medical service institute located in Incheon, Korea, and compared asthma mortality in dye workers to that of the general population and workers in other industries.

\section{Methods}

The study subjects consisted of 66,089 male workers who were employed by various companies in and around Incheon, and who underwent at least one medical examination during the period from 1995 to 2003. Female workers were excluded because none were reported to have died because of asthma. In Korea, manufacturing workers must undergo an annual health examination, which consists of a screening and confirmatory examination for those exposed to specific hazardous agents, such as benzene, silica dust, and noise. The general health examination includes screening and confirmatory examinations for hypertension, hypercholesterolemia, diabetes mellitus, liver disease, renal disease, and anemia, among other conditions ${ }^{10)}$.

The periodic medical examinations are conducted by an occupational service institute located in Incheon, Korea. We constructed a retrospective health examinee cohort consisting of 66,089 workers, including 904 workers from nine dye manufacturing companies, by collecting computerized health examination data from 1995 to 2003 . The data included each worker's resident registration number (unique personal identification number for Koreans), department, and company information.

Using the Korean Standard Industrial Classification (KSIC), the companies were divided into two categories: the dye industry and other industries. The KSIC has been revised based on the International Standard Industrial Classification (ISIC), and we distinguished industry groups using major sector categories. Each worker was assigned using this industrial classification according to the company employing the worker when he underwent his first health examination between 1995 and 2003. Employers can choose health service institutes and workers can change jobs, so the exposure circumstances can differ from the time of entry into the cohort. We, however, did not consider such changes.

Mortality data were matched to death statistics from the National Statistical Office (NSO) from 1995 to 2003 using resident registration numbers. The classification of the cause of death followed the tenth revision of the International Classification of Diseases (ICD-10). Death from asthma was defined by codes J45 (asthma) and J46 (status asthmaticus), and mortality from overall nonmalignant respiratory disease (NMRD) was defined by all $\mathrm{J}$ codes.

\section{Statistical analysis}

The observation period was $9 \mathrm{yr}$ from Jan. 1, 1995 to Dec. 31, 2003. The entry point into the cohort was the date of the first medical examination during the 1995 to 2003 period. If the worker survived until the termination point of the study, then person-years was calculated from the date of the first medical examination to Dec 31, 2003. If the worker died during the observation period, his person-years were calculated from the date of the first medical examination to the date of death.

The expected numbers were calculated from agespecific mortality rates for 5-yr age groups and 3-yr calendar periods, 1995 to1997, 1998 to 2000, and 2001 to 2003.

The indirectly standardized mortality ratios (SMRs) for all deaths, all non-malignant respiratory disease (NMRD), including asthma, and asthma were estimated by comparing the observed number of deaths with the expected number at the midpoint of each calendar period, that is, 1996, 1999, and 2002, for the Korean male population $^{11-13)}$.

Internal analyses were used to investigate the excess risk of death from all causes, all NMRD, and asthma between workers in the dye industry and other industries. Directly standardized rate ratios (SRRs) were calculated for 5-yr age groups and 3-yr calendar periods to compare the dye industry with other industries ${ }^{14)}$.

The program PAMCOMP (Person-years and Mortality Computation Program) was used to calculate personyears, SMRs, and exact Poisson confidence intervals $(\mathrm{CIs})^{15)}$. SRRs and exact Poisson CIs were computed using $\operatorname{LogXact} 8$ with tabulated data by PAMCOMP ${ }^{16)}$.

\section{Results}

Subjects aged 30 to $39 \mathrm{yr}$ constituted $36.14 \%$ of the cohort, the largest subgroup. The subject's age is the age at the time of the first medical examination (Table 1). The health service institute computerized the data on the health examinees and their companies beginning in 1995; therefore, $36.3 \%$ of the subjects were first included in this cohort in 1995. From then, new workers who underwent an initial medical examination at this health service institute entered into the cohort every year until 2003. For the dye industry, $60.29 \%$ of the workers were enrolled in 1995, which was much larger than the $35.97 \%$ for workers in other industries.

Twelve deaths from asthma were reported among 66,089 workers during the follow-up period. Eleven of these deaths occurred in the manufacturing industry sector (Table 2). Three deaths occurred in the dye industry, and 
Table 1. General characteristics of the study subjects

\begin{tabular}{|c|c|c|c|c|c|c|}
\hline & \multicolumn{2}{|c|}{ Dye industry } & \multicolumn{2}{|c|}{ Other industries } & \multicolumn{2}{|c|}{ All } \\
\hline & No. & $\%$ & No. & $\%$ & No. & $\%$ \\
\hline \multicolumn{7}{|l|}{ Age* } \\
\hline $20-29$ & 280 & 30.97 & 19,495 & 29.91 & 19,775 & 29.92 \\
\hline $30-39$ & 307 & 33.96 & 23,580 & 36.17 & 23,887 & 36.14 \\
\hline $40-49$ & 197 & 21.79 & 13,894 & 21.31 & 14,091 & 21.32 \\
\hline $50-59$ & 109 & 12.06 & 6,843 & 10.50 & 6,952 & 10.52 \\
\hline $60-69$ & 11 & 1.22 & 1,373 & 2.11 & 1,384 & 2.09 \\
\hline \multicolumn{7}{|l|}{ Year* } \\
\hline 1995 & 545 & 60.29 & 23,444 & 35.97 & 23,989 & 36.30 \\
\hline 1996 & 92 & 10.18 & 7,781 & 11.94 & 7,873 & 11.91 \\
\hline 1997 & 57 & 6.31 & 7,019 & 10.77 & 7,076 & 10.71 \\
\hline 1998 & 39 & 4.31 & 4,356 & 6.68 & 4,395 & 6.65 \\
\hline 1999 & 25 & 2.77 & 5,106 & 7.83 & 5,131 & 7.76 \\
\hline 2000 & 40 & 4.42 & 6,589 & 10.11 & 6,629 & 10.03 \\
\hline 2001 & 58 & 6.42 & 4,497 & 6.90 & 4,555 & 6.89 \\
\hline 2002 & 17 & 1.88 & 2,492 & 3.82 & 2,509 & 3.80 \\
\hline 2003 & 31 & 3.43 & 3,901 & 5.98 & 3,932 & 5.95 \\
\hline Total & 904 & 100.01 & 65,185 & 100 & 66,089 & 100 \\
\hline
\end{tabular}

* At the time of the first medical examination in the health service institute.

Table 2. Mortality cases due to asthma by sector

\begin{tabular}{lccc}
\hline The Korean Standard Industrial Classification & $\begin{array}{c}\text { Mortality due to } \\
\text { asthma }\end{array}$ & $\begin{array}{c}\text { No. of health } \\
\text { examinees }\end{array}$ & $\%$ \\
\hline Recreational, cultural, and sporting activities & 0 & 26 & 0.04 \\
Mining and quarrying & 0 & 50 & 0.08 \\
Private households with employed persons & 0 & 57 & 0.09 \\
Post and telecommunications & 0 & 111 \\
Public administration and defense & 0 & 112 & 0.17 \\
Transport & 0 & 240 & 0.36 \\
Wholesale and retail trade & 0 & 295 & 0.45 \\
Financial institutions and insurance companies & 0 & 319 & 0.48 \\
Real estate and renting and leasing & 0 & 360 & 0.54 \\
Electricity, gas, and water supply & 0 & 669 & 1.01 \\
Education & 0 & 1,027 & 1.55 \\
Business activities & 0 & 1,196 & 1.81 \\
Health and social work & 0 & 2,436 & 3.69 \\
Other community, repair, and personal service activities & 1 & 2,642 & 4.00 \\
Construction & 0 & 2,732 & 4.13 \\
Manufacturing & 11 & 53,817 & 81.43 \\
Total & 12 & 66,089 & 100 \\
\hline
\end{tabular}

nine deaths in other industries.

The all-cause mortality rate was significantly lower than in the general population $(\mathrm{SMR}=0.40,95 \%$ CI 0.24 0.63 ), while the asthma mortality was significantly higher than in the general population $(\mathrm{SMR}=9.03,95 \%$ CI 1.86
26.39) in dye industry workers (Table 3 ). In comparison to other industries, deaths from non-malignant respiratory diseases were higher in dye industry workers, but the difference was not statistically significant $(\mathrm{SMR}=2.0$, 95\% CI 0.41-5.86). 
Table 3. SMRs of death due to all causes, NMRD, and asthma

\begin{tabular}{|c|c|c|c|c|c|c|c|c|c|c|c|c|}
\hline \multicolumn{2}{|c|}{ Cause of death } & \multicolumn{3}{|c|}{$\begin{array}{c}\text { Dye industry } \\
\text { No. }=904 \text { PY }=6,284\end{array}$} & \multicolumn{4}{|c|}{$\begin{array}{c}\text { Other industries } \\
\text { No. }=65,185 \text { PY }=380,544\end{array}$} & \multicolumn{4}{|c|}{$\begin{array}{c}\text { All } \\
\text { No. }=66,089 \text { PY }=386,829\end{array}$} \\
\hline & Obs & Exp & SMR* & $95 \% \mathrm{CI}$ & Obs & Exp & SMR & $95 \% \mathrm{CI}$ & Obs & Exp & SMR & $95 \% \mathrm{CI}$ \\
\hline All causes & 19 & 47.1 & 0.40 & $0.24-0.63$ & 968 & 2714.6 & 0.36 & $0.33-0.38$ & 987 & 2761.7 & 0.36 & $0.34-0.38$ \\
\hline $\mathrm{NMRD}^{\dagger}$ & 3 & 1.5 & 2.00 & $0.41-5.86$ & 30 & 90.8 & 0.33 & $0.22-0.47$ & 33 & 92.3 & 0.36 & $0.25-0.50$ \\
\hline Asthma & 3 & 0.3 & 9.03 & $1.86-26.39$ & 9 & 20.8 & 0.43 & $0.20-0.82$ & 12 & 21.1 & 0.57 & $0.29-0.99$ \\
\hline
\end{tabular}

*standardized mortality ratio. "non-malignant respiratory disease.

Table 4. SRRs of death from all causes, NMRD, and asthma

\begin{tabular}{lcc}
\hline Cause of death & SRR $^{*}$ & $95 \%$ CI \\
\hline All causes & 1.09 & $0.00-1.19$ \\
NMRD $^{\dagger}$ & 6.04 & $4.00-9.44$ \\
Asthma & 23.29 & $11.05-58.83$ \\
\hline
\end{tabular}

*standardized rate ratio. †non-malignant respiratory disease.

Table 5. Characteristics of deaths due to asthma in the study subjects

\begin{tabular}{lccccl}
\hline $\begin{array}{c}\text { Case } \\
\text { Age at } \\
\text { death }\end{array}$ & $\begin{array}{c}\text { Year of } \\
\text { employment }\end{array}$ & $\begin{array}{c}\text { Year of } \\
\text { entry* }\end{array}$ & $\begin{array}{c}\text { Year of } \\
\text { death }\end{array}$ & \multicolumn{1}{c}{ The Korean Standard Industrial Classification } \\
\hline 1 & 57 & 1990 & 1995 & 2001 & Manufacture of synthetic coloring matter, tanning materials, and other \\
2 & 59 & 1988 & 1996 & 2000 & $\begin{array}{l}\text { coloring agents } \\
3\end{array}$ \\
41 & 1991 & 1996 & 1998 & Manufacture of general paints and similar products \\
4 & 54 & 1976 & 1995 & 2002 & Manufacture of other furniture \\
5 & 57 & 1991 & 1995 & 2001 & \\
6 & 55 & 1979 & 1995 & 2003 & Manufacture of wooden packing boxes, cable drums, and similar items \\
7 & 70 & 1996 & 1997 & 2003 & Other casting of nonferrous metals \\
8 & 59 & - & 1995 & 1998 & Manufacture of all other fabricated metal products \\
9 & 56 & 1987 & 1995 & 2003 & Metal product plating services \\
10 & 56 & 1994 & 1996 & 1999 & Mand \\
11 & 71 & 1987 & 1997 & 2003 & Manufacture of printed circuit boards \\
12 & 51 & 1994 & 1999 & 2003 & Non-hazardous waste disposal \\
\hline
\end{tabular}

*At the time of the first medical examination in the health service institute.

To perform an internal comparison with workers in other industries, we calculated the age-standardized SRRs for all-cause mortality, non-malignant respiratory disease mortality, and asthma mortality (Table 4). The all-cause mortality was nearly the same in both groups, while the mortality from non-malignant respiratory diseases and asthma was higher than for workers in other industries: $\mathrm{SRR}=6.04(95 \% \mathrm{CI} 4.00-9.44)$ and $\mathrm{SRR}=23.29(95 \% \mathrm{CI}$ 11.05-58.83), respectively.
Ten deaths from asthma occurred among active workers, and two presumably retired workers in their 70s died (Table 5). Three deaths were reported in the dye industry, three in the furniture and wood industries, one in paint manufacturing, two in metal production, and one in the plating industry. Two deaths (cases 7 and 12) involved office workers, and the other ten deaths were manufacturing workers. 


\section{Discussion}

Several studies have examined the occupational burden of asthma, and it was reported that the prevalence of physician-diagnosed asthma was higher for certain industries in the United States ${ }^{17)}$. In Caucasians, the prevalence and age- and sex-adjusted odds ratios (OR) were significantly elevated for the printing, publishing and allied industries $(\mathrm{OR}=2.4,95 \% \mathrm{CI} 1.2-5.0)$ and health care $(\mathrm{OR}=1.3,95 \%$ CI 1.0-1.7). In African-Americans, the ORs were elevated for the furniture, lumber, and wood (OR=1.3, 95\% CI 1.4-25.4), and entertainment and recreation $(\mathrm{OR}=4.1,95 \% \mathrm{CI} 1.1-15.9)$ industries. A cohort study investigated the mortality attributable to asthma among Swedish workers between 1981 and 1992 by linking official mortality statistics with occupational information in the 1980 national census ${ }^{6}$. It found that the smoking-adjusted SMRs were elevated in male farmers $(8 / 3.1, \mathrm{SMR}=146,95 \%$ CI 105-187), male professional drivers $(43 / 29.9, \mathrm{SMR}=144,95 \%$ CI $101-$ 209), and female hairdressers $(8 / 2.4, \mathrm{SMR}=332,95 \% \mathrm{CI}$ 102-561).

A few asthma mortality studies have used an occupational cohort for a specific industry. Langseth and Kjaerheim observed 3,143 women from 1951 to 2000 who were first employed in the pulp and paper industry between 1920 and $1993^{7)}$. Mortality due to non-malignant respiratory diseases $(\mathrm{SMR}=1.13,95 \% \mathrm{CI} 0.86-1.47)$ and the mortality due to chronic obstructive pulmonary disease (COPD) including asthma (SMR $=1.21,95 \%$ CI 0.77-1.57) were elevated slightly, but only 5 deaths from asthma were observed from 1960 to 2000 versus the 5.8 expected deaths. In a Norwegian cohort of 14,730 male workers employed for the first time in ferroalloy plants between 1933 and 1990 who had worked for at least 6 months in one of 12 plants, deaths were observed from 1962 to $1990^{9)}$. The mortality from bronchitis, emphysema, and asthma was elevated for the employees in the ferrosilicon/silicon-metal plants $(56 / 45.25, \mathrm{SMR}=1.24,95 \%$ CI 0.93-1.61), but not in ferromanganese/silicomanganese plants $(32 / 33.17$, $\mathrm{SMR}=0.96,95 \%$ CI $0.66-1.36$ ).

A case-control study of sulfite mill workers exposed mainly to sulfur dioxide, wood dust, and terpenes from the pulping process examined men who died between 1960 and 1989 and who were aged 40 to $75 \mathrm{yr}$ at death $(n=780)$; of these, 13 men died from asthma ${ }^{8)}$. An increased mortality from asthma $(\mathrm{OR}=2.8,90 \%$ CI $1.1-$ 6.8) associated with irritant gas exposure was detected compared to the referent group. Another study of 1,112 workers compensated for occupational asthma or aggravation of asthma between 1980 and 1993 reported increased SMRs for asthma $(2 / 0.1, \mathrm{SMR}=18.2)$ and COPD $(3 / 1.3, \mathrm{SMR}=2.3)^{18)}$.

Reactive dye is the most potent material that can elicit occupational asthma in the dye industry. It is inhaled in powder form; it then binds covalently to the hydroxyl groups on proteins and acts as a hapten ${ }^{19)}$. Occupational asthma caused by reactive dyes is prevalent in the dye industry, and the prevalence has been reported as $2.5 \%$, $5.9 \%$, and up to $14 \%{ }^{20-22)}$. It has even been reported that six employees who worked in factories near reactive dye factories developed occupational asthma due to reactive dye exposure ${ }^{20)}$. We conducted the present study because asthma mortality in dye manufacturing workers had not been assessed.

Our study has certain limitations. We could not adjust for smoking status due to the lack of data. Our study is a record linkage study, and we did not have enough computerized information about potential confounding factors such as smoking status, air pollution, and socioeconomic status for the observation period. We analyzed the excess risk assuming that the smoking status of dye industry workers was equal to workers in other industries, because they were mostly manufacturing workers and lived in the same area. However, smoking is a crucial confounding factor for asthma, and lack of information on smoking is an important limitation of our study. We did not differentiate manufacturing workers from office workers because only two deaths were observed in office workers. Although the workers could have changed jobs and employers could have changed health service institutes during the study period, we did not consider this an issue because it was impossible to track the work histories of all workers. Since occupational asthma with a prolonged exposure to asthmagens can progress to chronic status even if the exposure has ceased, our findings may still reflect chronic asthma status. Death certificates can occasionally be misclassified because chronic obstructive lung disease (COPD) and asthma can become confused in the elderly. Therefore, we compared non-malignant respiratory diseases including both COPD and asthma in the dye industry with other industries and found a significant increase in the SRR of non-malignant respiratory diseases for dye industry workers. Loss of follow-up could occur in cases of emigration, but we consider it to be a very small portion of the whole. The possibility exists of a healthy worker effect because compensated occupational asthmatics exposed to isocyanates, the most frequent occupational asthmagen, could have left the cohort. In addition, because only three deaths from asthma were observed in dye industry workers, very wide confidence intervals due to the low statistical power constitute a final limitation of our study.

Reactive dyes have been increasingly used as coloring agents in the textile industry. In addition to manufacturing workers in the dye industry, a study has reported occupational asthma in a wool and cotton dyer handling reactive dyes ${ }^{23}$. Considering the high risk of asthma death in the dye industry, more active preventive measures should be taken. Our study could be generalized to dye 
manufacturing workers beyond Korean workers from a preventive point of view.

Two of three deaths involving the furniture and wood industries and the one death in paint manufacturing could possibly have been related to isocyanate exposure. In addition, the effect of chromium exposure cannot be ruled out for the two deaths in metal production and one death in the plating industry. We did not consider deaths from these asthmagens in this study, but special actions should also be taken regarding these occupational asthmagens to prevent deaths from occupational asthma.

\section{Conclusions}

Workers in the dye industry are exposed to various dyes, including reactive dye, a well-known occupational asthmagen. We studied 66,089 male workers, including 904 workers in the dye industry, who underwent medical examinations from 1995 to 2003 at a medical service institute located in Incheon, Korea, and compared the mortality from asthma in dye manufacturing workers with that of the general population and workers in other industries.

The asthma mortality was significantly higher than in the general population (SMR=9.03, 95\% CI 1.86-26.39) in dye industry workers. In addition, the risk for asthma mortality was higher in dye industry workers than in workers in other industries (SRR $=23.29,95 \%$ CI $11.05-$ 58.83). As occupational asthma is a life-threatening disease, special considerations and preventive measures must be taken for workers in the dye industry.

\section{References}

1) Park JW, Kim CW, Kim KS, Choi SY, Kang DB, Ko SH, Won JU, Yang JY and Hong CS: Role of skin prick test and serological measurement of specific IgE in the diagnosis of occupational asthma from exposure to vinyl sulphone reactive dyes. Occup Environ Med 58, 411-416 (2001)

2) Shinka T, Sawada Y, Morimoto S, Fujinaga T, Nakamura J and Ohkawa T: Clinical study on urothelial tumors of dye workers in Wakayama city. Urology 146, 1504-1507 (1991)

3) Kim Y, Park J and Shin YC: Dye-manufacturing workers and bladder cancer in South Korea. Arch Toxicol 81, 381-384 (2007)

4) Kang SK, Ahn YS and Kim KJ: Recent advances in occupational health research in Korea. Ind Health 42, 91-98 (2004)

5) Scheffer AL and Taggart VS: The national asthma education program: expert panel report guidelines for the diagnosis and management of asthma. National heart, lung, and blood institute. Med Care 31(Suppl), MS20-MS28 (1993)

6) Toren K and Horte LG: Asthma mortality and occupation in Sweden 1981-1992. Am J Ind Med 31, 678-681 (1997)

7) Langseth $\mathrm{H}$ and Kjaerheim $\mathrm{K}$ : Mortality from non- malignant respiratory diseases in a cohort of female pulp and paper workers in Norway. Occup Environ Med 63, 741-745 (2006)

8) Andersson E, Nilsson T, Persson B, Wingren G and Toren K: Mortality from asthma and cancer among sulphide mill workers. Scand J Work Environ Health 24, 12-17 (1998)

9) Hobbesland A, Kjuus H and Thelle DS: Mortality form non-malignant respiratory diseases among male workers in Morwegian ferroalloy plants. Scand J Work Environ Health 23, 342-350 (1997)

10) Won JU, Song J, Ahn YS, Roh J and Park CY: Analysis of factors associated the workers' health status using periodic health examination data by size of enterprises. Yonsei Med J 43, 14-19 (2002)

11) Korea National Statistical Office. Annual report on the cause of death statistics 1996. Daejeon: Korea National Statistical Office, 1997.

12) Korea National Statistical Office. Annual report on the cause of death statistics 1999. Daejeon: Korea National Statistical Office, 2000

13) Korea National Statistical Office. Annual report on the cause of death statistics 2002. Daejeon: Korea National Statistical Office, 2003.

14) Checkoway H, Pearce N, Kriebel D. Research methods in occupational epidemiology. New York: Oxford University Press, 2004: 141-144.

15) Taeger D, Sun Y, Keil U and Straif K: A standalone windows application for computing exact person-years, standardised mortality ratios and confidence intervals in epidemiological studies. Epidemiology 11, 607-608 (2000)

16) Cytel Software. LogXact: Software for Exact Poisson Regression. Cambridge: Cytel Software, 1996.

17) Bang KM, Hnizdo E and Doney B: Prevalence of asthma by industry in the US population: a study of 2001 NHIS data. Am J Ind Med 47, 500-508 (2005)

18) Liss GM, Tarlo SM, Banks D, Yeung KS and Schweigert M: Preliminary report of mortality among workers compensated for work-related asthma. Am J Ind Med 35, 465-471 (1999)

19) Park HS, Kim YJ, Lee MK and Hong CS: Occupational asthma and IgE antibodies to reactive dyes. Yonsei Med J 30, 298-304 (1989)

20) Park HS, Kim JW and Hong CS: The prevalence of specific IgE and $\mathrm{IgG}$ to reactive dye-human serum albumin conjugate in workers of a dye factory and neighboring factories. J Korean Med Science 6, 63-68 (1991)

21) Chida $T$ and Ueheta $T$ : Prevalence of allergic diseases among synthetic chemical workers. Jpn J Ind Health 29, 358-365 (1987)

22) Lee KJ, Moon YH, Roh J, Park HS and Hong CS: Health characteristics and symptoms of workers in reactive dye industries. Korean J Prev Med 23, 338344 (1990)

23) Romano C, Sulotto F, Pavan I, Chiesa A and Scansetti G: A new case of occupational asthma from reactive dyes with severe anaphylactic response to the specific challenge. Am J Ind Med 21, 209-216 (1992) 